\title{
Biopelet dari Eceng Gondok, Sekam, Dedak, Serbuk Gergaji dan Tongkol Jagung Ditinjau dari Komposisi Terhadap Kualitas Biopelet
}

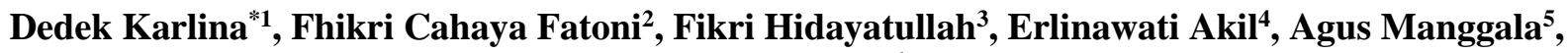 K. A. Ridwan ${ }^{6}$}

1,2,3,4,5,6Program Studi Teknik Energi, Jurusan Teknik Kimia, Politeknik Negeri Sriwijaya, Indonesia

Email: 1dedekkarlina10@gmail.com, ${ }^{2}$ cahayafatoni@ gmail.com, ${ }^{3}$ fikrihidaya14@gmail.com

\begin{abstract}
Abstrak
Sebagian besar kebutuhan bahan bakar dipenuhi dari bahan bakar fosil dengan berbagai kegunaan untuk mendukung kegiatan masyarakat. Namun, ketersediaan bahan bakar saat ini semakin berkurang, terutama bahan bakar fosil. Biopellet merupakan bahan bakar biomassa padat dengan kerapatan dan keseragaman ukuran yang lebih baik daripada biomassa. Variabel yang mempengaruhi kesempurnaan pembakaran, ukuran partikel, dan karakteristik material. Tujuan dari penelitian ini adalah untuk mendapatkan bio pellet yang memenuhi standar SNI 8021-2014. Hasil penelitian untuk komposisi campuran eceng gondok, serbuk gergaji, dan tongkol jagung dapat diketahui bahwa kualitas pellet terbaik terdapat pada komposisi campuran eceng gondok 50\%:50\% serbuk gergaji dan diameter $8 \mathrm{~mm}$. pellet dengan kadar air 2,41\%, kadar abu 2,02 \%, zat terbang 63,98\%, kadar karbon $31,59 \%$, dan nilai kalor 5148,334 (kal/gr). Untuk campuran sekam padi dan dedak, komposisi $60 \%$ sekam padi: dedak $40 \%$ dan pellet diameter 9 mm dengan nilai kalor 5517,0128 (cal/gr), kadar air 8,81\%, karbon tetap 9,10\%, zat mudah menguap 78 0,77\%, dan kadar abu 3,32\%. Serta untuk komposisi campuran $70 \%$ tongkol jagung : hasil torefikasi tongkol jagung 30\% dengan diameter pellet $8 \mathrm{~mm}$, nilai kalor 5.271.7799 (cal/gr), kadar air 5,99\%, abu kandungan 3,13\%, kandungan volatile matter 72,06\%, dan kandungan karbon terikat $18,83 \%$. Dimana pellet tersebut telah mencapai Standar Nasional Indonesia 8021-2014.
\end{abstract}

Kata kunci: biopellet,biomasa,kualitas,nilai kalor.

\section{Judul Biopellet from Water Hyacinth, Husk, Bran, Sawdust and Corn Overview of Composition on The Quality of Biopellet}

\begin{abstract}
Most of the fuel needs are met from fossil fuels with various uses to support community activities. However, the availability of fuel is currently decreasing, especially fossil fuels. Currently. Biopellet is a solid biomass fuel with better density and size uniformity than biomass. Variables that affect combustion perfection, particle size, and material characteristics. The purpose of this study was to obtain bio pellets that meet the standards of SNI 8021-2014. The results of the research for the composition of the mixture of water hyacinth, sawdust, and corn cobs can be seen that the best quality of pellet is found in the composition of the mixture of water hyacinth 50\%: $50 \%$ sawdust and $8 \mathrm{~mm}$ diameter pellet with a moisture content of $2.41 \%$, ash content of $2.02 \%$, volatile matter $63.98 \%$, carbon content $31.59 \%$, and calorific value 5148.334 (cal/gr). For a mixture of rice husks and bran, the composition of $60 \%$ rice husks: $40 \%$ bran and $9 \mathrm{~mm}$ diameter pellet with a calorific value of 5517.0128 (cal/gr), water content $8.81 \%$, fixed carbon $9.10 \%$, volatile matter $780.77 \%$, and $3.32 \%$ ash content. As well as for the composition of the mixture of $70 \%$ corn cobs: the results of $30 \%$ corn cob torefication with a pellet diameter of 8 $\mathrm{mm}$, the calorific value of 5,271,7799 (cal/gr), water content $5.99 \%$, ash content $3.13 \%$, volatile matter content $72.06 \%$, and the bound carbon content is $18.83 \%$. Where the pellet has reached the Indonesian National Standard 8021-2014.
\end{abstract}

Keywords: BioPellet, Biomass, Calorific Value, Quality.

\section{PENDAHULUAN}

Kebutuhan bahan bakar selama ini banyak dipenuhi dari bahan bakar fosil dengan berbagai macam penggunaannya alam mendukung aktifitas masyarakat. namun ketersediaan bahan bakar saat ini sedang mengalami penurunan khususnya bahan bakar fosil. Hal tersebut dikarenakan kebutuhan masyarakat akan bahan 
bakar fosil meningkat mencapai 7\% tiap tahunnya, melebihi penggunaan energi dunia yang hanya 2,6\% per tahun. Berdasarkan data tersebut, saat ini Indonesia krisis bahan bakar fosil permasalahan ini dapat diselesaikan dengan memproduksi bahan bakar alternatif yang dapat menggantikan bahan bakar fosil dari bahan yang tersedia di alam, murah dan dapat diperbarui [1]. Eceng gondok, limbah tanaman padi, tongkol jagung, dan serbuk gergaji merupakan limbah yang dapat merusak lingkungan dan belum di manfaatkan secara optimal. Jika dapat dimanfaatkan secara baik dan dengan penanganan yang baik pula didukung teknologi sederhana, kebijakan khusus dari pemerintah dan perhatian dari masyarakat, akan berdampak positif dalam mengatasi permasalahan energi. Biomasa dapat digunakan sebagai bahan bakar langsung, namun penggunaannya memiliki beberapa kekurangan diantaranya adalah kadar air yang tinggi, bentuk dan ukuran yang tidak seragam, densitas rendah, kerapatan energi yang rendah serta mudah terserang mikroorganisme perusak [2]. Peningkatan kualitas biomasa sebagai bahan bakar dapat dilakukan dengan cara melakukan konversi menjadi bentuk yang lebih baik. Konversi yang dilakukan dapat memudahkan dalam penanganan, transportasi, penyimpanan, peningkatan daya bakar, peningkatan efisiensi bakar, bentuk yang lebih seragam, dan kerapatan energi yang lebih besar. Dengan menerapkan proses torefikasi pada bahan baku biomassa dengan suhu $200-300^{\circ} \mathrm{C}$ pada tekanan atmosfer tanpa pengaruh oksigen dapat menyebabkan menguapkan air dapat menguap, sebagian volatil matter yang terkandung dalam biomassa dan sisa dari fraksi karbon biomassa dapat berkurang [3].

Ukuran partikel menjadiakan lebih kecil maka dapat meningkatkan kerapatan sehingga memiliki dampak dalam perbaikan kualitas biomassa. Biopelet adalah bahan bakar biomassa berbentuk pelet yang memiliki keseragaman ukuran, bentuk, kelembapan, dan kandungan energi. Pada umumnya proses pembuatan biopelet, biomassa diumpankan ke dalam pelet mill yang memiliki dies dengan ukuran diameter 8-11 mm dan 15-25 mm. Untuk penggunaan perekat sesuai dengan persyaratan bahwa penambahan perekat ke dalam campuran bahan biopelet adalah 0,5-5\% [4][5]. Proses pembuatan biopelet dapat meningkatkan kerapatan spesifik biomassa lebih dari $1000 \mathrm{~kg} / \mathrm{m}^{3}$.

Perekat adalah suatu bahan yang memiliki kemampuan untuk mengikat dua benda memalui ikatan permukaan. ada beberapa jenis perekat yang dapat digunakan dalam pembuatan biopelet seperti perekat aci, perekat tanah liat, perekat getah karet dan perekat getah pinus. Tujuan penelitian ini adalah mengetahui pengaruh komposisi bahan baku sehingga didapatkan pellet yang sesuai SNI 8021-2014.

\section{METODE PENELITIAN}

\subsection{Bahan}

Bahan yang digunakan pada penelitian ini adalah eceng gondok, sekam padi, dedak, serbuk gergaji, tongkol jagung dan tepung tapioka. Bahan tersebut diperoleh dari gasing dan pasar, Sumatera Selatan.

\subsection{Metode}

Penelitian ini dimulai dengan tahap preparasi eceng gondok, sekam padi, dedak dan serbuk gergaji, serta tongkol jagung. Bahan tersebut dihaluskan menggunakan grinder dan di ayak sesuai kebutuhan. Selanjutnya menimbang masing-masing bahan sebanyak 500 gr. Pada bahan baku tongkol jagung, 30\% dari bahan baku tongkol jagung dipisahkan untuk dilakukan proses torefikasi terlebih dahulu, dengan suhu $300^{\circ} \mathrm{C}$ selama 5 jam di dalam furnace, sehingga didapatkan arang dari hasil torefikasi tersebut yang akan dicampurkan dengan $70 \%$ bahan baku dari tongkol jagung tersebut.

Proses pencetakan pelet dilakukan dengan cara menghidupi mesin diesel terlebih dahulu dan menunggu sampai suhu alat pencetak flatdie mencapai $>100{ }^{\circ} \mathrm{C}$. Bila sudah memasukkan adonan ke dalam hopper kemudian bahan akan di transfortasikan oleh screw conveyor menuju pellet mill. pencetak yang berdiameter 8 $\mathrm{mm}, 9 \mathrm{~mm}$ dan panjang 1-3 cm. selanjutanya mengeringkan biopelet yang telah terbentuk untuk menghilangkan uap panas pelet saat keluar dari mesin biopelet. Analisa produk biopelet meliputi analisa fisik (nilai kalor metode ASTM D5685-11a) dan analisa kimia (kadar air, kadar karbon, kadar abu, dan kadar zat terbang Metode ASTM D7583-10).

\section{HASIL DAN PEMBAHASAN}

\subsection{Pengaruh Komposisi Campuran Terhadap Kadar Air}

Dari hasil pengamatan yang dilakukan, kadar air yang diperolehdari komposisi campuran berkisar antara 2\% - 6\% .Dengan kadar air terendah terdapat pada komposisi campuran eceng gondok dengan serbuk gergaji dengan rasio (50:50)\% sebesar 2,41\% dan kadar air tertinggi pada komposisi campuran sekam padi dan dedak 
dengan rasio (50:50)\% sebesar 9,18\%. Sehingga kadar air pada biopelet tersebut telah memenuhi standar, yang dilihat berdasarkan Badan Standarisasi Nasional SNI 8021 : 2014.

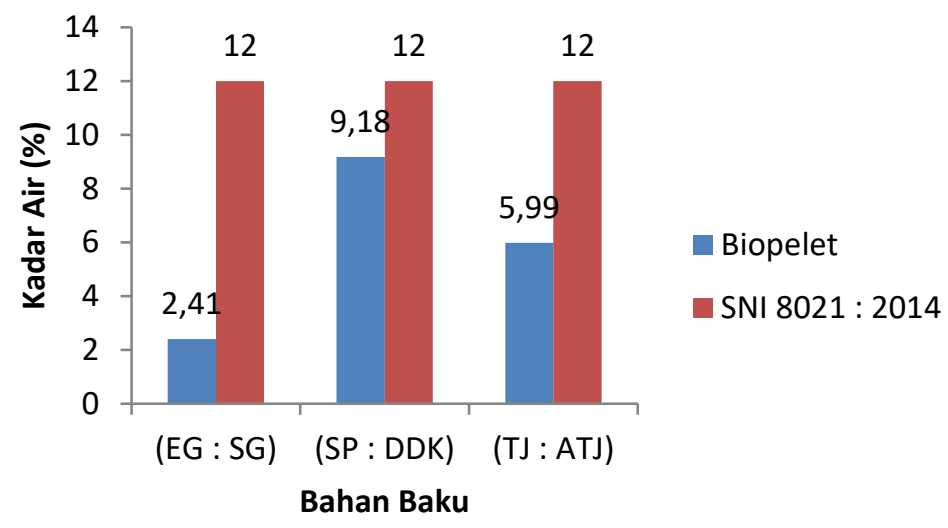

Gambar 1. Grafik Pengaruh Komposisi Campuran Terhadap Kadar Air

Faktor lainnya yaitu terdapat pada pengemasan biopelet.Biopelet yang baru saja dilakukan pencetakan, harus dijemur terlebih dahulu selama 1 hari. Agar uap panas yang masih melekat pada biopelet dapat teruapkan. Apabila biopelet langsung dilakukan pengemasan, uap panas yang masih mengandung air tadi akan berkumpul dikemasan dan kembali turun serta menyatu ke biopelet yang telah selesai dicetak

\subsection{Pengaruh Komposisi Campuran Terhadap Kadar Abu}

Berdasarkan Pengamatan yang dilakukan, kadar abu yang diperoleh berkisar antara 2\% - 3\%. Hasil pengujian menunjukan bahwa kadar abu yang dihasilkan dari komposisi campuran sekam padi dan dedak dengan rasio (50:50)\% memiliki nilai kadar abu yang paling tinggi yaitu sebesar 3,4\%. Sedangkan kandungan kadar abu paling sedikit diperoleh dari komposisi campuran eceng gondok dengan serbuk gergaji dengan rasio (50:50)\% yaitu sebesar $2,41 \%$. Nilai kadar abu yang dihasilkan pada penelitian ini telah memenuhi standar Amerika dan Prancis akan tetapi, berdasarkan Badan Standarisasi Nasional SNI 8021 : 2014. Kadar abu tersebut masih cukup tinggi. Kadar abu di pengaruhi oleh jenis bahan baku karena jumlah mineral setiap jenis bahan baku berbeda beda. Semakin tinggi silika pada biomassa maka kualitas biopelet akan semakin rendah. Hasil kadar abu pada biopelet dapat dilihat pada Gambar 2.

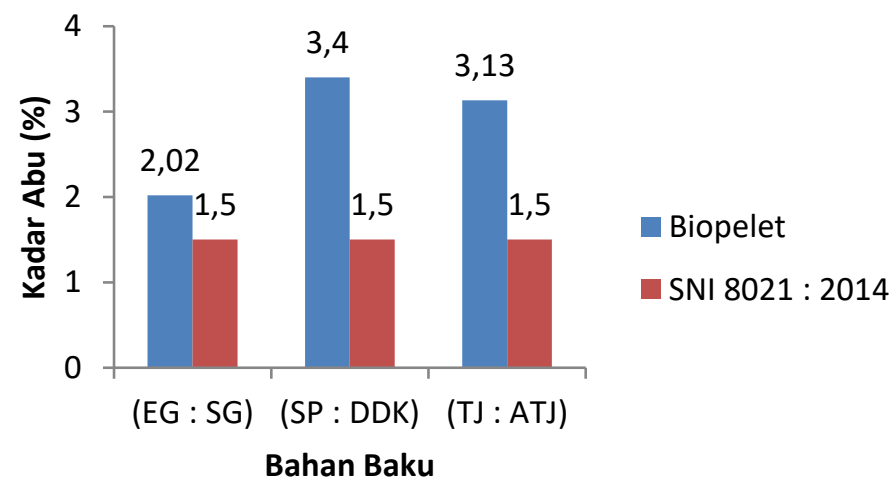

Gambar 2. Grafik Pengaruh Komposisi Campuran Terhadap Kadar Abu

\subsection{Pengaruh Komposisi Campuran Terhadap Kadar Kadar Zat Terbang}

Berdasarkan hasil pengamatan, kadar zat terbang yang diperoleh berkisar antara 63\% - 78\%. Kadar zat terbang paling tinggi terdapat pada komposisi campuran sekam padi dan dedak dengan rasio (50:50)\% dengan persentase $78,22 \%$. Sedangkan paling sedikit dengan menggunakan komposisi campuran eceng gondok dengan serbuk gergaji dengan rasio (50:50)\% sebesar $63.98 \%$. Nilai kadar volatile mater ditentukan untuk menentukan jumlah asap pada proses pembakaran biopelet karena semakin besar nilai volatile mater maka asap yang ditimbulkan pada proses pembakaran semakin besar. Besarnya kandungan asap yang ditimbulkan dari 
pembakaran biopelet menyebabkan polusi udara. Hasil kadar zat terbang pada biopelet dapat dilihat pada Gambar 3.

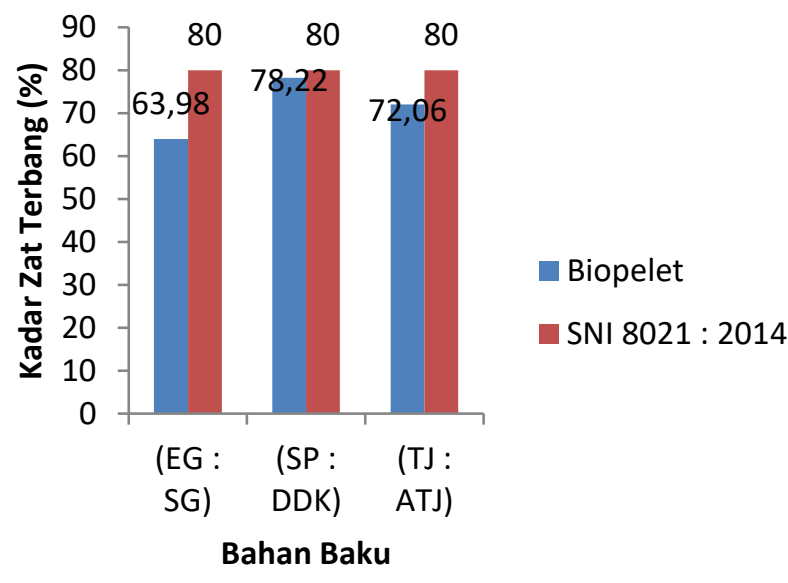

Gambar 3. Grafik Pengaruh Komposisi Campuran Terhadap Kadar Zat Terbang

\subsection{Pengaruh Komposisi Campuran Terhadap Kadar Karbon Terikat}

Kadar karbon terikat dipengaruhi oleh unsur penyusunnya seperti karbon, hydrogen, dan oksigen [6]. Berdasarkan hasil pengamatan, kadar karbon tetap yang diperoleh berkisar antara 9\% - 31\%. Kadar karbon tetap tertinggi terdapat pada komposisi campuran eceng gondok dengan serbuk gergaji dengan rasio (50:50)\% yaitu sebesar $31,59 \%$. Sedangkan kadar karbon tetap terendah terdapat pada komposisi campuran sekam padi dan dedak dengan rasio (50:50)\% yaitu sebesar 9,2\% sehingga, pada komposisi campuran sekam padi dan dedak dengan rasio (50:50)\% masih sangat rendah apabila dilihat berdasarkan Badan Standarisasi Nasional SNI 8021 : 2014. Hasil kadar karbon terikat pada biopelet dapat dilihat pada Gambar 4.

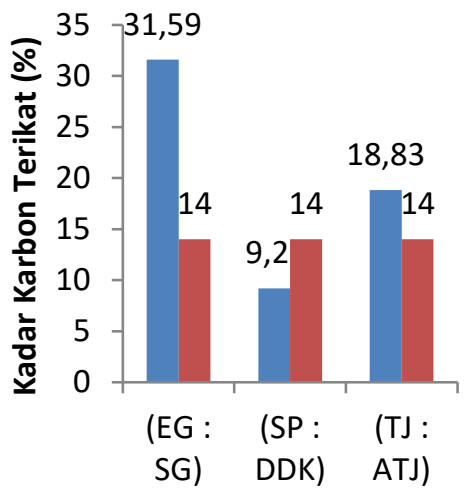

Biopelet

SNI $8021: 2014$

Bahan Baku

Gambar 4. Grafik Pengaruh Komposisi Campuran Terhadap Kadar Karbon Terikat

Untuk meningkatkan fixed carbon biopelet, bahan baku yang digunakan harus yang memiliki komposisi lignin yang tinggi, kadar air karbon terikat tergantung dari kandungan lignin, semakin besar kandungan lignin maka karbon tetap semakin tinggi.

\subsection{Pengaruh Komposisi Campuran Terhadap Nilai Kalor}

Nilai kalor didefinisikan sebagai panas yang dilepaskan dari pembakaran sejumlah kuantitas unit bahan bakar (massa) dimana produknya dalam bentuk ash, gas $\mathrm{CO}_{2}, \mathrm{SO}_{2}$, nitrogen dan air, tidak termasuk air yang menjadi uap (vapor) [7]. Berdasarkan hasil pengamatan, nilai kalor bipelet yang diperoleh berkisar antara $5.148,3340 \mathrm{kal} / \mathrm{gr}$ - 5.389,4630 kal/gr. Biopelet dengan komposisi campuran eceng gondok dengan serbuk gergaji dengan rasio (50:50)\% merupakakan biopelet dengan nilai kalor terendah dengan nilai sebesar $5.148,3340 \mathrm{kal} / \mathrm{gr}$ sedangkan biopelet dengan komposisi campuran sekam padi dan dedak dengan rasio (50:50)\% 
merupakan biopelet dengan nilai kalor tertinggi sebesar 5.389,4630kal/gr kal/gr.Hasil nilai kalor pada biopelet dapat dilihat pada Gambar 5.

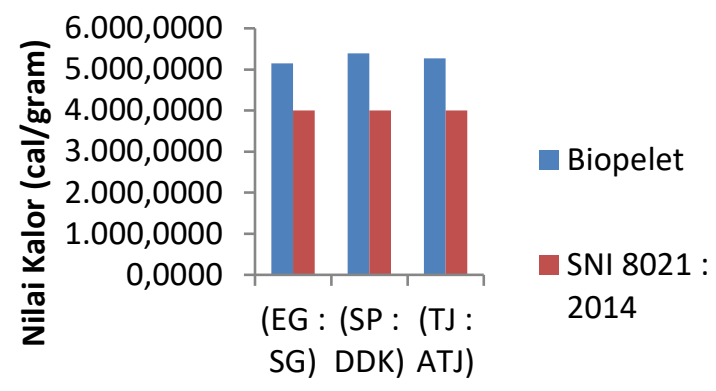

Bahan Baku

\section{Gambar 5. Grafik Pengaruh Komposisi Campuran Terhadap Nilai Kalor}

Dari grafik tersebut menunjukan bahwa diameter biopelet tidak terlalu berpengaruh kepada nilai kalor. Tetapi, diameter biopelet mempengaruhi efisiensi energi bahan bakar. Kemudian biopelet dengan campuran komposisi 50\% eceng gondok : 50\% serbuk gergaji menunjukkan nilai kalor yang lebih tinggi dibandingkan dari komposisi campuran eceng gondok dan serbuk gergaji yang lain pada saat pembuatan, karena dengan semakin banyak penambahan komposisi serbuk gergaji pada saat pembuatan biopelet maka hasilnya dapat berpengaruh pada nilai kalor. Serta pemanfaatan proses torefikasi pada tongkol jagung akan memperbaiki sifat-sifat bahan baku dan bahan bakar dari segi nilai kalor, kadar air, grindability, sifat higroskopik dan meminimalisir asap pembakaran, sehingga terjadi peningkatan nilai kalor yang dihasilkan

\section{KESIMPULAN}

Berdasarkan hasil dan pembahasan diatas, maka kesimpulan yang dapat diperoleh adalah bahwa biopelet dengan kualitas terbaik, yang telah memenuhi standar SNI 8021-2014, yaitu sekam padi : dedak dimana di dapatkan nilai kalor tertinggi $5389 \mathrm{cal} / \mathrm{gr}$. Kualitas biopelet yang optimal terdapat pada biopelet dengan komposisi $60 \%$ sekam padi : $40 \%$ dedak dan flat die $9 \mathrm{~mm}$ dengan nilai kalor 5517,0128 cal/grm, kadar air $8,81 \%$, fixed carbon $9,10 \%$, volatile matter $78,77 \%$, dan kadar abu 3,32\%. Biopelet ini telah mencapai Standar Nasional Indonesia 8021-2014. Hal ini pula dipengaruhi oleh jumlah komposisi bahan baku yang digunakan, serta dengan menambahkan proses torefikasi pada tongkol jagung dapat memberikan pengaruh dalam meningkatkan kualitas biopelet seperti menurunkan kadar air dan kadar zat terbang, serta meningkatkan nilai kalor pada biopelet. Akan tetapi, kadar abu juga meningkat.

\section{DAFTAR PUSTAKA}

[1] M. Falah and N. Nelza, "Pembuatan Biopelet dari Limbah Tandan Kosong Kelapa Sawit (TKKS) sebagai Bahan Bakar Terbarukan," Regional Development Industry \& Health Science, Technology and Art of Life, pp. 90-95.

[2] M. Zuhdi, "Kulit Kayu Pinus Sebagai Fortifier Biopelet Batang Singkong", Elearning IPB, Bogor: Institute Pertanian Bogor, 2018. http://Tep.Fateta.Ipb.Ac.Id/Elearning/.(Accessed June 25 2009)

[3] W. Liliana, Peningkatan Kualitas Biopelet Bungkil Jarak Pagar Sebagai Bahan Bakar Melalui Teknik Karbonisasi, Fakultas Teknologi Pertanian, 2010.

[4] Azhar and H. Rustamaji, "Bahan Bakar Padat Dari Biomassa Bambu Dengan Proses Torefikasi dan Densifikasi," Jurnal Rekayasa Proses, vol. 3, pp. 26-29, 2009.

[5] T. Bantacut, D. Hendra and R. Nurwigha, "The Quality of Biopellet From Combination of Palm Shell Charcoal and Plam Fiber," Jurnal Teknologi Industri Pertanian, vol. 23, pp. 1-12, 2013.

[6] P. Basu, Biomass gasification and pyrolisis, practical design and theory, United State: Academic Press, 2010.

[7] D. Patabang, "Studi Karakteristik Termal Briket Arang Kulit Buah Kakao," Jurnal Mekanikal, vol. 2, pp. 23-31, 2011. 